$\begin{array}{ll} & \text { Etnográfica } \\ \text { etnográfica } & \text { Revista do Centro em Rede de Investigação em }\end{array}$

Antropologia

vol. 21 (1) | 2017

Vol. 21 (1)

\title{
Da resistência africanista ao suvenir africano: artesanato, nação e fantasmagoria na ilha da Boa Vista, Cabo Verde
}

From Africanist resistance to African souvenir: handicraft, nation and phantasmagoria on the island of Boa Vista, Cape Verde

\section{Eduarda Rovisco}

\section{(2) OpenEdition}

\section{Journals}

\section{Edição electrónica}

URL: https://journals.openedition.org/etnografica/4798

DOI: 10.4000/etnografica.4798

ISSN: 2182-2891

\section{Editora}

Centro em Rede de Investigação em Antropologia

\section{Edição impressa}

Data de publição: 1 fevereiro 2017

Paginação: 5-26

ISSN: 0873-6561

\section{Refêrencia eletrónica}

Eduarda Rovisco, «Da resistência africanista ao suvenir africano: artesanato, nação e fantasmagoria na ilha da Boa Vista, Cabo Verde», Etnográfica [Online], vol. 21 (1) | 2017, posto online no dia 14 março 2017, consultado o 11 fevereiro 2022. URL: http://journals.openedition.org/etnografica/4798 ; DOI: https://doi.org/10.4000/etnografica.4798

\section{(c) (7) \&}

Etnográfica is licensed under a Creative Commons Attribution-NonCommercial 4.0 International License. 


\section{Da resistência africanista ao suvenir africano: artesanato, nação e fantasmagoria na ilha da Boa Vista, Cabo Verde}

\section{Eduarda Rovisco}

Nos últimos dez anos, o crescimento do turismo e da imigração na ilha da Boa Vista (Cabo Verde) originou a abertura de um elevado número de lojas de artesanato, maioritariamente pertencentes a imigrantes senegaleses que se dedicam à venda de artefactos provenientes do seu país ou por si produzidos nesta ilha. Estes imigrantes têm sido alvo de práticas discriminatórias, sendo sistematicamente acusados de venderem objetos não representativos da cultura cabo-verdiana e de "assediarem os turistas”. Este artigo propõe uma reflexão em torno deste comércio, articulando-o com os processos de construção da nação cabo-verdiana e com o papel do artesanato nesta construção.

PALAVRAS-CHAVE: artesanato, suvenir, identidade nacional, Boa Vista, Cabo Verde.

From Africanist resistance to African souvenir: handicraft, nation and phantasmagoria on the island of Boa Vista, Cape Verde - In the last ten years, the growth of both tourism and immigration on the island of Boa Vista (Cape Verde) has led to the opening of an increased number of handicraft shops, mostly owned by Senegalese immigrants who sell artifacts which are either locally crafted or shipped from Senegal. These immigrants have been facing a number of discriminatory practices, while being systematically accused of "harassing tourists" and of selling objects that are not representative of Cape Verdean culture. This article proposes to reflect on this handicraft trade in relation to the processes of nation building in Cape Verde and on the role of crafts in these processes.

KEYWORDS: handicraft, souvenir, national identity, Boa Vista, Cape Verde.

ROVISCO, Eduarda (eduarda.rovisco@gmail.com) - Instituto Universitário de Lisboa (ISCTE-IUL), CRIA, Lisboa, Portugal. 
ESTE ARTIGO RESULTA DE UMA INVESTIGAÇÃO EM CURSO REALIZADA no âmbito de um projeto de pós-doutoramento sobre turismo e identificação nacional em Cabo Verde e suporta-se em materiais colhidos no decurso de duas etapas de trabalho de campo efetuadas entre finais de 2011 e meados de 2015 nas ilhas de Santiago, São Vicente e Boa Vista. ${ }^{1}$ Na primeira secção deste texto apresenta-se uma síntese dos discursos sobre artesanato em distintas etapas dos processos de identificação nacional, incorporando materiais resultantes de uma pesquisa no arquivo do Centro Nacional de Artesanato e de um conjunto de entrevistas realizadas com produtores e comerciantes de artesanato nas três ilhas. Nas duas últimas secções são revelados dados de uma análise sobre a aceleração do crescimento do turismo, da imigração, do comércio de artesanato e dos seus conflitos na ilha da Boa Vista.

\section{DA RESISTÊNCIA AFRICANISTA AO SUVENIR AFRICANO}

\section{Da era da "grande e confrangedora penúria"}

No período colonial, os intelectuais implicados na construção, tematização e inquirição da cultura popular cabo-verdiana conferiram pouca atenção à sua componente material. Entre a escassa bibliografia dedicada ao tema contam-se dois textos de Nuno de Miranda (1968) e António Carreira (1983 [1968]) e um conjunto de curtas referências proferidas no âmbito do debate atiçado pelas polémicas declarações de Gilberto Freyre sobre a "instabilidade cultural" que afirmou ter encontrado no arquipélago, no decurso da sua visita a Cabo Verde em 1951. Para Freyre, esta "instabilidade" podia ser atestada pela “ausência, entre esses mesmos ilhéus, de artes populares em que se exprimisse uma saudável interpenetração das culturas que neles se cruzam”, ausência que derivaria do "pudor [do ilhéu] de ser africano" (Freyre 2001 [1953]: 277, 276).

Embora o retrato da cultura cabo-verdiana traçado por Freyre, que tanto desapontou os intelectuais da geração "claridosa", ${ }^{2}$ tenha sido objeto de inúmeras críticas, a ideia de "ausência de artes populares" não foi contundentemente negada (Venâncio e Silva 2010). Baltasar Lopes, figura de proa desta geração, numa longa crítica às reflexões de Freyre, refere sobre esta questão:

I Este projeto é financiado pela Fundação para a Ciência e a Tecnologia (Portugal), através da bolsa SFRH/BPD/72387/2010.

2 Articulada em torno da revista Claridade, esta geração urdiu um modelo identitário que apresentava Cabo Verde como um caso de regionalismo português. Segundo Gabriel Fernandes, este modelo, influenciado pelo luso-tropicalismo, concebia as componentes africanas da cultura como resíduos que se haviam diluído nas ilhas do Barlavento, encontrando-se praticamente confinadas à ilha de Santiago. O retrato do arquipélago efetuado por Freyre contraria este modelo, retirando-lhe parte do seu suporte teórico (Fernandes 2002: 78-106). Ver ainda, sobre este assunto, Anjos (2002: 77-136) e Fernandes (2006: 143-178). 
“É já coisa sabida - e Gilberto Freyre não deixa de a apontar - a indigência das formas decorativas de uma arte popular que, diga-se desde já, precisa de ensinamentos técnicos e de possibilidades de venda. [...] Mas a verdade verdadeira é que não temos uma arte decorativa popular. Onde as nossas cerâmicas? Onde as nossas rendas regionais? Onde os nossos bordados? Onde os artefactos que se sirvam, com uma regionalidade inteligente, da matéria-prima que as ilhas oferecem? É curioso e convida à meditação, que esta indigência de acento regional aconteça no artesanato" (Lopes 2010 [1956]: 250-251). ${ }^{3}$

Veja-se ainda, fora do quadro de produção da geração "claridosa", como a robustez das críticas de Manuel Ferreira às reflexões de Freyre vacila neste ponto, levando-o a afirmar que "devemos buscar" nas condições ecológicas do arquipélago, aliadas à "falta de escoamento e encorajamento à produção [...] a quase impossibilidade da existência de uma arte que se imponha, de pronto, a olhos de europeus ávidos de exotismo ou de expressiva criação artística local" (Ferreira 1967: 51). ${ }^{4}$

Esta ideia da exiguidade da arte popular nas últimas décadas do período colonial ecoa ainda em textos mais recentes, como revela o seguinte excerto da autoria de José Luís Hopffer Almada:

"A situação era de tal forma preocupante que os especialistas se revezam e contradizem na busca de explicações plausíveis para a aparente bizarria de tal fenómeno. Para uns, é na pobreza em recursos susceptíveis de servir de matéria-prima que residiria a razão fundamental desse estado decadente do artesanato caboverdiano. Para outros, a razão desse estado de coisas radicaria na geral inaptidão do caboverdiano para as artes plásticas, inaptidão que teria sido herdada da tradição muçulmana, consabidamente avessa à figuração e trazida para as ilhas por algumas etnias escravizadas. Essa propalada inaptidão seria tão congénita ao crioulo das ilhas como a sua natural vocação para outras artes, como a música ou a dança. [...] Facto é que, à data da independência, a situação era de grande e confrangedora penúria" (Almada 2008: 116- 117). ${ }^{5}$

3 Note-se que, enquanto Baltasar Lopes parecia procurar rendas, bordados e cerâmica que pudessem confirmar a sua leitura do arquipélago como região portuguesa, Gilberto Freyre pareceu buscar objetos que exprimissem "uma sobrevivência africana cultivada com algum carinho" (Freyre 2001 [1953]: 276), refletindo assim duas conceções divergentes sobre a cultura do arquipélago.

4 Também Nuno de Miranda, referindo-se ao labor decorativo do homem cabo-verdiano, refere: "A decoração é praticamente inexistente no arquipélago. [...] Porque a decoração está-lhe na alma" (Miranda 1968: 349-350).

5 Vejam-se ainda as afirmações de Mesquitela Lima sobre esta matéria numa entrevista conduzida por João Lopes Filho (1984: 20-21). 


\section{Da fase do espanto: a emergência do artesanato como expressão da resistência à opressão colonial}

Alguns meses antes da independência, chegaram ao Mindelo três artistas plásticos - Bela Duarte, Luísa Queirós e Manuel Figueira - que, em pouco tempo, iriam revolucionar a produção, visibilidade e estatuto do artesanato cabo-verdiano. Terá sido sob o lema de manter viva a tecelagem cabo-verdiana e "inspirados nas resistências culturais deste povo [e] na obra de Amílcar Cabral" (Queirós, em Lança 2010) que estes artistas se lançaram na construção da Cooperativa de Produção Artesanal Resistência (1976) no Mindelo, convertida em Centro Nacional de Artesanato (CNA) no final de 1977.

Num documento intitulado "Proposta de Estatutos do Centro Nacional de Artesanato", datado de 1978, podemos ler que "[o] CNA exerce a sua actividade em cooperação com as estruturas do Partido, os departamentos estatais, as organizações sociais e as organizações de massas" e que seriam suas atribuições: (a) "[p]romover o estudo das diversas formas de artesanato caboverdiano, como expressão da cultura popular, com vista à sua identificação, conservação, fomento e renovação"; (b) "[i]nventariar as matérias-primas nacionais susceptíveis de aproveitamento em moldes artesanais"; (c) "[f]omentar a produção artesanal popular de artigos utilitários, tendo em consideração as necessidades e tradições populares"; (d) “[p]romover o ensino das técnicas artesanais, tanto as já tradicionais em Cabo Verde como as mais modernas de âmbito universal"; (e) "[i]ncentivar a iniciativa criadora das massas populares no âmbito do artesanato"; (f) "[d] esenvolver o espírito cooperativista na produção artesanal"; (g) "[p]romover a divulgação do artesanato cabo-verdiano, tanto no País como no exterior". ${ }^{6}$

Entre as atividades do CNA, destaco a produção na área dos têxteis (recuperação e renovação da panaria e introdução de técnicas de tapeçaria e batique), ${ }^{7}$ as missões de investigação realizadas em outras ilhas, o apoio concedido a

6 Arquivo do CNA (ACNA), caixa 89. Note-se que Manuel Figueira entendia por artesanato "[A]quilo que é produzido pelo artesão, consistindo esta produção de objectos que podem ser artísticos ou não, utilitários ou não, servindo-se o produtor de meios rudimentares, ferramentas ou instrumentos, que podem considerar como que o prolongamento da mão ou do corpo humano, em geral, sendo este o motor e a máquina que desprende a energia para produzir a peça que contém um conjunto de valores tradicionais, carregados de grande dimensão cultural". Dividia-o em "três ramos": "Artesanato artístico-decorativo, com a função de embelezar, de cumprir somente um papel estético; Artesanato artístico-utilitário com função utilitária e apresentando simultaneamente valores estéticos; e Artesanato utilitário concebido e executado, sem preocupações artísticas, para dar resposta às necessidades materiais do dia-a-dia" (em "Programa de Desenvolvimento do Artesanato Nacional", sem data, presumivelmente de 1981 , caixa 89 , ACNA).

7 O CNA possuía uma delegação regional na Praia, inicialmente dirigida por Luís Tolentino e, a partir de 1983, por Gustavo Duarte. Nesta secção, legatária da oficina existente no Centro de Informação e Turismo, produziam-se, maioritariamente, objetos feitos a partir de coco, chifre, osso ou carapaça de tartaruga. 
vários artesãos das áreas da tecelagem, olaria, cestaria, bordados, costura, etc., e as inúmeras exposições realizadas, que atribuíram uma inédita centralidade ao artesanato na agenda cultural do país.

A emergência do artesanato após a independência, tornando-o uma das áreas mais criativas da construção nacional durante a I República, espelha a ideologia revolucionária e africanista deste período, apresentando o povo como herói da resistência ao colonialismo e o artesanato como expressão dessa resistência produtora de "objetos militantes". Sublinhando-se a presença e valor de técnicas trazidas para o arquipélago por escravos (visíveis nos teares e nos panos ou nos métodos de modelagem e cozedura dos barros), celebrava-se o berço africano de muitos artefactos. Neste contexto, a alegada apatia da produção artesanal no período precedente começa a ser explicada através da opressão colonial sobre o povo que, com a liberdade, pôde por fim dar largas à sua capacidade criadora. Atente-se nas palavras de Manuel Figueira, a propósito de uma exposição realizada em julho de 1975:

“Os objectivos da exposição eram exactamente desmistificar o conceito corrente de que o povo de Cabo Verde nada produzia de carácter artístico-utilitário (ideia bem urdida pelo colonialismo para sufocação total da actividade local); mostrar que todas as ilhas ao longo dos anos e apesar de todas as carências, souberam resistir culturalmente". ${ }^{8}$

Três décadas após a publicação de Aventura e Rotina, onde Gilberto Freyre (2001 [1953]) relatou a sua viagem ao arquipélago, a equipa do CNA havia já revelado uma "arte popular" cabo-verdiana, item indispensável na construção das identidades nacionais. Embora salientasse as componentes africanas, o popular construído no CNA apresentou contornos certamente incómodos para o autor brasileiro. Desde logo, o demótico do CNA, refletindo a conjuntura do país, associou-se ao revolucionário, remetendo mais para a transformação do presente do que para a conservação do passado. Com efeito, a equipa do CNA parecia menos interessada em reproduzir objetos de um passado remoto do que em transformá-los, adaptando-os a novos usos e introduzindo novas técnicas. Se, como demonstrou Néstor García Canclini, o popular é uma construção híbrida, ${ }^{9}$ no caso do CNA parece ter havido um reforço dessa hibridez. Este reforço é detetável em objetos que emergem da rasura das fronteiras entre arte e artesanato, de que são exemplo algumas tapeçarias que constituem obras importantes na história de arte cabo-verdiana. Esta hibridez é ainda notória

8 "Complemento do Relatório da Exposição 5 de Julho de 1975", com data de 24/08/1975, caixa 82, ACNA.

9 Servindo-me das palavras de João Leal, “[o] popular é - literalmente - o produto do encontro de duas culturas: a cultura que lá estava e que não sabia que era popular e a cultura de quem chega lá e a nomeia como popular" (2009: 475). 
na própria constituição da equipa do CNA, que agregou experientes tecelões, jovens aprendizes mindelenses e artistas plásticos formados na Escola Superior de Belas-Artes de Lisboa.

Em 1989, coincidindo sensivelmente com o fim da I República, estes artistas plásticos afastaram-se desta instituição. O CNA viria a ser extinto em 1997 , após ter perdido a componente criativa e laboratorial (resultante do cruzamento da investigação com a experimentação) que o caracterizou durante os seus primeiros 11 anos, sob a direção de Manuel Figueira (1978-1989). A saída de Manuel Figueira do CNA encerra assim um capítulo na história do artesanato cabo-verdiano, que deve ser lido como elemento integrante da construção nacional da I República, efetuada sob a égide do africanismo.

\section{Dos tempos da "desafricanização" dos espíritos e das coisas e dos modos de nomeá-las}

Embora o processo de "desafricanização da nação" tenha sido complexo, ${ }^{10}$ começando a definir-se logo após o colapso do projeto de unidade com a Guiné-Bissau (1980), terá sido após a realização das primeiras eleições pluripartidárias, em 1991, vencidas pelo Movimento para a Democracia (MpD), que os procedimentos desafricanizantes se amplificaram, manifestos na substituição da bandeira ou na reposição da toponímia colonial (Fernandes 2002: 180-181). A partir de então este processo far-se-á a par com o progressivo crescimento do turismo e da imigração. Estes fenómenos determinaram a emergência de um novo ciclo na produção e comércio de artesanato, cada vez mais articulado com o turismo e dominado por objetos provenientes do Senegal, comercializados por imigrantes, maioritariamente oriundos deste país. Uma das consequências mais imediatas destas alterações é detetável na própria linguagem, passando o termo artesanato a ser acoplado aos qualificativos "cabo-verdiano" ou "africano". O "artesanato cabo-verdiano" passa a definir-se, paradoxal e genericamente, como aquele que não é “africano", ou seja, que não é oriundo do continente, e a constituir-se como vítima da concorrência exercida pelo seu rival, o exótico e barato "artesanato africano", vendido por imigrantes.

É neste novo contexto que o governo voltará a intervir na área do artesanato. Em 2011, o ministro da Cultura reúne artesãos do arquipélago no primeiro Fórum Nacional de Artesanato, que se repetiria nos anos seguintes. Desta primeira reunião resultaram uma série de recomendações que visavam incrementar a produção, distribuição, formação, associativismo, articulação com o design e implementar a certificação. Nesse mesmo ano foi criado o

10 Para Gabriel Fernandes: “a desafricanização dos espíritos não foi algo linear, de que pudesse resultar um novo ciclo de ocultamento da herança afro-negra; ela traduz uma fase de despartidarização ou desideologização da cultura, possibilitando a atribuição de um novo conteúdo simbólico ao suposto resgate identitário operado sob a sigla de retorno" (Fernandes 2002: 178). 
Centro Nacional de Artesanato e Design, mas a situação de permanente estrangulamento financeiro protelaria a aplicação de algumas destas medidas. Todavia, graças a esta intervenção, o artesanato voltava a ser notícia frequente na imprensa cabo-verdiana e, em muitos locais, os artesãos conseguiram associar-se e expor regularmente a sua produção. Em 20 de março de 2016, o Partido Africano da Independência de Cabo Verde (PAICV), que se encontrava no poder desde 2001 , perdeu as eleições legislativas, desconhecendo-se, à data de elaboração deste texto, as orientações do novo governo do MpD para esta matéria.

A importância conferida ao artesanato na I República e as inerentes operações de gentrificação de tantos artefactos, convertidos subitamente em símbolos da nação, terão certamente contribuído para a popularização e generalização do uso do termo "artesanato", limitando as possibilidades de emergência de outros termos. Note-se que muitos estabelecimentos comerciais têm inscrito no seu nome a palavra "suvenir", continuando, no entanto, a ser designados pela população como "lojas de artesanato", o que só em parte pode ser explicado pelo facto de a maioria dos objetos expostos ser artesanal. ${ }^{11}$ Seguindo a terminologia utilizada no arquipélago, uso o termo artesanato em conformidade com os significados atribuídos pelos meus interlocutores, que parecem contrapô-lo mais à indústria do que à arte (Lima 2009) e adotar a definição atrás enunciada, elaborada por Manuel Figueira. Não obstante, nas próximas secções refiro-me sempre a artefactos com funções de suvenir (Swanson e Timothy 2012; Horodyski, Manosso e Gândara 2012; González 2008; Freire-Medeiros e Castro 2007; Stewart 1996 [1993]), dependentes do mercado turístico.

\section{O CRESCIMENTO DO TURISMO E DA IMIGRAÇÃO NA BOA VISTA}

De acordo com os dados divulgados pelo Instituto Nacional de Estatísticas (INE), entre 2000 e 2015 o número de indivíduos que terá dado entrada nos estabelecimentos hoteleiros do país passou de 145.076 para 569.387 (INE 2005: 34, 2016: 34). ${ }^{12}$ Apesar da aposta na diversificação de produtos e

11 Conforme a tipologia proposta por Gordon, os suvenires podem ser divididos em: (a) produtos pictóricos (postais, livros e outros materiais com imagens do destino); (b) réplicas e ícones (por exemplo, miniaturas de monumentos); (c) marcadores (objetos como porta-chaves, canecas, $t$-shirts com a inscrição da marca do destino); (d) objetos piece of rock (fósseis, conchas, pedras, flores, etc.); (e) produtos locais (artesanato ou produtos alimentares, produzidos localmente) (Horodyski, Manosso e Gândara 2012; Swanson e Horridge 2006: 673). Em Cabo Verde, os produtos pictóricos, réplicas, ícones e marcadores têm uma presença muito menor do que os produtos locais, o que em parte é explicável pela debilidade da indústria no país. Ainda que muitas lojas vendam $t$-shirts, canecas e outros produtos industriais com a inscrição da marca Cabo Verde - na sua quase totalidade importados da China e vendidos também em lojas chinesas -, uma grande parte dos marcadores é produzida por artesãos.

12 Dando continuidade à tendência registada desde 2009, em 2015, a maioria dos hóspedes seria proveniente do Reino Unido (22,2\%), seguindo-se os alemães (13,4\%) e portugueses (10,9\%). [continua] 
destinos, expressa na criação do slogan "One Country... Ten Destinations", este setor continua marcado pela hegemonia do turismo balnear, para o qual concorreu o "boom turístico" na ilha da Boa Vista, após a inauguração do seu aeroporto internacional em 2007. Entre 2000 e 2015, o número de hóspedes nos estabelecimentos hoteleiros desta ilha passou de 9402 para 181.771 (INE 2005: 43, 2016: 42). Nos anos de 2011 a 2013, a Boa Vista foi a ilha que recebeu mais hóspedes neste arquipélago (INE 2012: 54, 2013: 8, 2014: 8). Em 2015, a Boa Vista (com 32\%) e o Sal (com 43\%) captaram 75\% do número total de hóspedes registados no país (INE 2016: 42).

O número de quartos nos estabelecimentos hoteleiros na Boa Vista passou de $161 \mathrm{em} 2000$ para 2625 em 2015 (INE 2005: 14/anexo, 2016: 15). Quase 90\% dos quartos existentes em 2015 pertenciam a apenas quatro hotéis, dois dos quais (Riu Karamboa e Riu Touareg) detinham cerca de 66\% do número total de quartos. Estes quatro hotéis, fortemente vigiados e excludentes, instalados em praias desertas e afastadas das povoações, são propriedade de empresários ou grupos económicos estrangeiros e todos funcionam em regime "tudo incluído", limitando assim as saídas dos turistas e, consequentemente, os rendimentos que a população residente poderia auferir com o turismo.

Deve ser notado que estes hotéis possuem as suas próprias lojas, discotecas, bares, restaurantes, piscinas, ginásio e outros equipamentos desportivos, assistência médica e um programa de animação que inclui espetáculos de dança e música ao vivo. Constituindo zonas livres dos supostos "perigos da alteridade", estes hotéis reproduzem o modelo apelidado de "enclaves" ou "bolhas turísticas" (Adiyia et al. 2015; Jaakson 2004; Urry e Larsen 2011), distinguindo-se em tudo do contexto social e cultural em que se inserem. Com efeito, excluindo os trabalhadores maioritariamente nacionais, Cabo Verde parece encontrar-se ausente nestes hotéis, não só no que concerne aos hóspedes, como também ao nível da arquitetura, decoração, alimentação e animação, estas últimas praticamente confinadas à realização de uma noite temática cabo-verdiana por semana. ${ }^{13}$ Nas várias conversas com guias, animadores e outros funcionários de diferentes hotéis, pude constatar que os meus interlocutores consideravam que a maioria dos hóspedes revelava um profundo desconhecimento e, em alguns casos, algum desinteresse pela música, gastronomia e outros itens da cultura cabo-verdiana. Atente-se nas palavras de um músico local que atua regularmente em dois destes hotéis, a propósito do aumento de músicos europeus no

[continuação] Nesse ano, os hóspedes residentes em Cabo Verde somaram 8,7\% das entradas (INE 2016: 36). No que concerne à ilha da Boa Vista, em 2015, os hóspedes do Reino Unido corresponderam a $31 \%$ do total das entradas, seguindo-se os da Alemanha (19\%), Bélgica e Holanda (14\%), Portugal (9\%), França (8\%), Itália (6\%) (INE 2016: 42).

13 Os dois hotéis da cadeia Riu possuíam um restaurante temático cabo-verdiano. Contudo, vários turistas se queixaram das dificuldades em conseguir efetuar reservas nestes restaurantes. Sobre alimentação, turismo e "bolhas ambientais culinárias", ver Cohen e Avieli (2004). 
Sal, contratados por dominarem o reportório ocidental conhecido pelos turistas: "o que traz os turistas para a Boa Vista é o sol e a praia. Estarem em Cabo Verde ou nas Canárias é igual. A maioria dos turistas é inglesa, não sabe nada da cultura e da música cabo-verdiana e nem quer saber, quer ouvir a música deles".

O crescimento do turismo na Boa Vista desencadeou um aumento acentuado da população residente, estimada em 4209 residentes em 2000, em 9162 em 2010 (INE: s/d.) e em 14.451 em 2015 (INE 2015: 36). Este aumento resultou de três fluxos migratórios com distintas dimensões e origens geográficas. Em primeiro lugar, em termos de dimensão, um fluxo maioritário constituído por indivíduos oriundos de Santiago e outras ilhas do país. Em segundo lugar, um fluxo proveniente de países da Comunidade Económica dos Estados da África Ocidental (CEDEAO), composto sobretudo por jovens do sexo masculino oriundos da Guiné-Bissau (na sua maioria empregados na construção civil e segurança) e do Senegal (em grande parte envolvidos no comércio de artesanato). De acordo com as estimativas dos dirigentes das associações de imigrantes destes dois países, em 2015, residiriam na Boa Vista cerca de 1500 bissau-guineenses e 300 senegaleses. Por último, um fluxo composto por imigrantes da União Europeia (UE), em especial de Itália, envolvidos em atividades relacionadas com o turismo ou com o ramo imobiliário.

Segundo o INE, 15,5\% (2239) da população residente na Boa Vista em 2014 seria estrangeira, sendo esta a ilha com o maior número relativo de residentes estrangeiros (2015: 41-42). Estima-se que o número real de estrangeiros seja mais elevado, uma vez que muitos não possuem visto ou cartão de residência, esquivando-se assim a responder aos inquéritos. ${ }^{14}$ Note-se que, na sua quase totalidade, os imigrantes da CEDEAO entraram legalmente em Cabo Verde ao abrigo do protocolo de livre circulação em vigor nesta região, ${ }^{15}$ que lhes permite permanecer 90 dias sem visto no país. Contudo, uma grande parte não conseguiu obter autorização de residência, por não ter conseguido reunir a extensa lista de documentação exigida pelas autoridades cabo-verdianas, em alguns casos impossível de obter (cf. UCI/OFII 2014: 47-48).

O crescimento do número de imigrantes provenientes de países da CEDEAO em Cabo Verde tem sido explicado através do desemprego estrutural, da instabilidade política e dos conflitos armados em muitos destes países, bem como do crescimento económico, em especial no setor do turismo, e da estabilidade política em Cabo Verde. No entanto, este crescimento deve ser relacionado com as disposições relativas à livre circulação no espaço da CEDEAO e com a impossibilidade de emigração direta para a Europa. Com efeito, o fenómeno

14 No Censo realizado em 2010 (UCI/OFII 2014: 18), foram contabilizados pelo INE 14.373 estrangeiros residentes em Cabo Verde: 8783 dos quais da CEDEAO e 2446 provenientes da Europa. De entre os Estados da CEDEAO, a Guiné-Bissau surgia como o país com mais imigrantes em Cabo Verde (5544), seguida pelo Senegal (1634) e pela Nigéria (740).

15 Ver, por exemplo, Adepoju (s/d.). 
da imigração em Cabo Verde não pode ser dissociado do progressivo endurecimento das restrições à imigração por parte da UE, consubstanciadas numa miríade de práticas de externalização da sua fronteira e de criminalização da imigração. Estas práticas têm direcionado cidadãos da CEDEAO para o arquipélago, que passou a ser descrito como país de trânsito e espaço liminar onde se eterniza a espera por uma oportunidade para chegar à Europa. ${ }^{16}$ Deste modo, Cabo Verde constitui hoje um terreno privilegiado para observar o corolário das orientações europeias em matéria de mobilidade, assentes na intensificação da mobilidade dos seus cidadãos (nomeadamente no âmbito do turismo) e na criminalização da mobilidade dos cidadãos de países africanos.

Este aumento acelerado do turismo e da imigração e, consequentemente, da população residente, que revolucionou a pequena vila de Sal Rei (elevada a cidade em 2010), não foi devidamente planificado, carecendo a população de infraestruturas básicas diversas. Estas carências são particularmente gravosas no que concerne à habitação, abastecimento de água e energia, saúde, saneamento básico, tratamento de lixo, educação e transportes. Grande parte da população de Sal Rei encontrava-se alojada num bairro insalubre, sugestivamente apelidado de "Barraca", não coberto pelas redes de abastecimento de água e de energia elétrica. ${ }^{17} \mathrm{O}$ custo de vida disparou nos últimos anos e a taxa de desemprego na Boa Vista subiu de 5,7\%, em 2010, para 17,9\% em 2014, sendo assim superior à taxa de desemprego global do país que, no mesmo ano, se situava nos 15,8\% (INE 2015: 52). ${ }^{18}$

Além da dureza das condições de vida e das dificuldades decorrentes de não possuírem autorização de residência, muitos dos imigrantes provenientes da CEDEAO enfrentam ainda o racismo e a "maurabeza" 19 de muitos boa-vistenses

16 Sobre a crítica aos usos da categoria "país de trânsito" e sua aplicação ao contexto cabo-verdiano, ver Barbosa (2014). Sobre as orientações do governo cabo-verdiano em matéria de imigração ver, por exemplo, UCI (2012). No que concerne à investigação produzida sobre o fenómeno do crescimento da imigração em Cabo Verde, veja-se, por exemplo, Barbosa (2014), Furtado (2012), Marcelino (2011), Rocha $(2009,2013)$. Relativamente aos estudos sobre a emigração senegalesa, veja-se, por exemplo, Bava (2005), Diop (2008), Fall e Bochaca (2012), Poeze (2010), Sall (2010). Sobre a articulação destes fenómenos na ilha da Boa Vista, veja-se Jung (2013).

17 Em 2010, foram contabilizadas pelo INE, 2305 residentes neste bairro. Na primavera de 2015, o número de residentes seria muito superior e o bairro encontrava-se já circundado por uma muralha de prédios em construção no âmbito do programa do governo "Casa para Todos", nos quais se projetava realojar parte da população residente em barracas.

18 Em 2015 existiriam 1793 trabalhadores ao serviço nos estabelecimentos hoteleiros da ilha (INE 2016: 11). Destes, apenas 58 estavam enquadrados como pessoal permanente (INE 2016: 19). O trabalho na hotelaria foi sistematicamente caracterizado pela sua precariedade, pelas longas e penosas jornadas de trabalho e salários que não permitem fazer face ao elevado custo de vida.

19 Termo usado num documento da UCI/OFII (2014: 61) para designar o avesso da morabeza, i.e., o avesso da cordialidade cabo-verdiana para com os forasteiros. Deve ser notado que, na Boa Vista, esta "maurabeza" é também dirigida à população oriunda de Santiago, frequentemente descrita como sendo mais "africana" (cf. Fernandes 2002: 90-95; Fikes 2007). 
e, no caso dos senegaleses, uma declarada hostilidade em relação à sua atividade no comércio de artesanato.

\section{PRODUÇÃO E COMÉRCIO DE ARTESANATO NA BOA VISTA}

Na primavera de 2015, existiam 49 estabelecimentos comerciais de artesanato em Sal Rei: 23 pequenas lojas no Mercado de Feirantes e no Mercado Municipal, dois quiosques e 24 lojas no centro histórico. No total, seis estabelecimentos eram publicitados como lojas de "artesanato cabo-verdiano", embora grande parte dos objetos expostos em três destas seis lojas fosse proveniente do Senegal, Brasil e China. Numa entrevista realizada com uma das proprietárias destes três estabelecimentos, esta cabo-verdiana lamentou ter nas suas lojas pouco "artesanato cabo-verdiano", queixando-se do seu elevado preço, da "falta de criatividade" dos artesãos nacionais e da diminuta produção por parte dos boa-vistenses, praticamente circunscrita ao trabalho de um pequeno grupo de oleiros da Escola de Olaria do Rabil.

Grande parte da produção destes oleiros consiste num figurado com função de suvenir, produzido em série através de moldes. Nas prateleiras da loja desta oficina proliferam tartarugas (o símbolo da ilha), elefantes, pais natais e outras réplicas de objetos em barro que podemos encontrar em Portugal, e ainda pequenas placas magnéticas com a forma da ilha ou de tartarugas, sendo este o produto mais vendido. ${ }^{20}$ Esta oficina integrava a quase totalidade das excursões realizadas por turistas, sendo descrita pelos guias como oficina de "olaria tradicional cabo-verdiana" 21 e como um dos poucos locais onde se podia adquirir "verdadeiro artesanato cabo-verdiano".

Excluindo a olaria do Rabil, a produção de artesanato por parte de boa-vistenses era praticamente invisível, destacando-se a pequena produção de um cesteiro da Povoação Velha que executava chapéus, cestos e balaios, por vezes miniaturizados, e de um pequeno grupo de mulheres que efetuava rendas, bordados, costura e bijuteria, não vendendo, na sua maioria, a sua produção para lojas. Em 2014, foi criada uma associação de artesãos que contava com 14 associados em maio de 2015, mas apenas o seu presidente, Alcides Morais,

20 Esta ilha possui alguns dos mais importantes locais de nidificação de tartarugas da espécie Caretta caretta. Nos meses de verão, a observação da desova de tartarugas constitui uma das atividades propostas aos turistas.

21 A Escola de Olaria do Rabil terá sido criada em 1959 (Lima 1997: 132), tendo sido dirigida por um oleiro português até à independência. Após um período de letargia, António Mosso Monteiro (filho de uma oleira do Rabil) conseguiu paulatinamente reanimar esta oficina. Num artigo de 1983, Leão Lopes afirmava que a olaria da Boa Vista havia sofrido "influências de formas estranhas trazidas por um oleiro português, que originaram na produção boa-vistense um hibridismo às vezes bizarro e desagradável" (Lopes 1983: 15). Sobre olaria cabo-verdiana, ver também Madureira (2012) e Marçal (2012). 
oleiro do Rabil, vivia exclusivamente do artesanato. A criação desta associação deve ser entendida no âmbito de um conjunto de ações promovidas nos últimos anos pela Câmara Municipal da Boa Vista com o propósito de reverter o quadro de anemia que caracteriza a atual produção de artesanato por parte dos boa-vistenses ${ }^{22}$ e aumentar a sua presença no comércio de suvenires nesta ilha, dominado por objetos importados do Senegal.

\section{Da produção e comércio de "artesanato africano"}

De acordo com os depoimentos de comerciantes que se encontravam há mais tempo em Sal Rei, a venda de artesanato da costa ocidental africana por imigrantes começou por ser feita na rua por um pequeno grupo de bissau-guineenses e senegaleses. Logo após o termo da construção do Mercado Municipal e do Mercado de Feirantes (2002, 2003), a Câmara Municipal da Boa Vista arrendou algumas lojas destes mercados a imigrantes envolvidos neste negócio, circunscrevendo-o assim a espaços definidos. Em 2015, estes dois mercados possuíam 23 pequenas lojas de venda de artesanato (sete no Mercado Municipal e 16 no Mercado de Feirantes), arrendadas a comerciantes do continente, na sua quase totalidade provenientes do Senegal. ${ }^{23}$

A partir de finais da última década, o aumento de pessoas oriundas do Senegal originou a abertura de 17 lojas no centro de Sal Rei e de oito na Povoação Velha, em muitos casos partilhadas por vários comerciantes. A maioria destes não possuía qualquer relação prévia com a produção ou venda de artesanato no Senegal, embora muitos tenham trabalhado em outros ramos do comércio informal em Dacar. Em Cabo Verde, a sua inserção na atividade terá começado sobretudo pela venda ambulante. Apesar de a Câmara Municipal da Boa Vista ter deixado de emitir licenças de venda ambulante em 2012, um grupo de jovens senegaleses trabalhava nas praias, no deserto de Viana e nas ruas de Sal Rei, circulando com os objetos escondidos em mochilas.

Todas as lojas possuem o mesmo tipo de objetos: roupa e sacos produzidos a partir dos coloridos tecidos estampados wax print, máscaras, cestaria elaborada através da técnica de espiral cosida, sandálias em couro, miniaturas de tambores e corás, bijuteria, estatuetas de madeira zoomórficas (tartarugas, elefantes, rinocerontes, leões, etc.) e antropomórficas (pensadores, dançarinas, colonos

22 A população mais idosa tende a enaltecer a qualidade do artesanato produzido na Boa Vista antes da independência, em especial a olaria, cestaria, rendas e bordados, objetos feitos de carapaça de tartaruga por Emiliano Silva, e por vezes a tecelagem praticada em tempos mais remotos. Almeida (2003: 108) e Lima (1997: 131) referem que alguns exemplares desta tecelagem terão sido exibidos nas exposições universais de Londres (1862) e Antuérpia (1885).

23 Na primavera de 2015, a renda mensal paga à Camara Municipal da Boa Vista era de cerca de 60 euros, sendo a área das lojas muito exígua. Em dezembro de 2015, este mercado terá sido desativado no âmbito do projeto de requalificação de Sal Rei que previa a construção de um hotel neste local. Os comerciantes terão sido deslocados para o espaço da antiga fábrica Ultra. 
e mulheres com cargas sobre a cabeça) e quadros com motivos que designam como "africanos" elaborados na Boa Vista. Na sua maioria, estes objetos constituem ficções visuais (Steiner 1994: 35) produzidas no estilo que Ladd definiu, servindo-se de um texto de Wole Soyinka, como "neo-tarzanismo": "an oversimplified, fictionalised meta-narrative of Africa which must include leopard skins, zebra stripes, dark wood and tall thin women" (Ladd 2012: 202).

Tal como foi assinalado por Freire-Medeiros e Castro a propósito das lojas de suvenires do Rio de Janeiro, também estas lojas tendem a eliminar distâncias geográficas e cronológicas, lembrando os wonder cabinets, pelo seu caráter heterotópico assente na construção de um "lugar-outro" exótico (Freire-Medeiros e Castro 2007; ver também Venkatesan 2009).

Com exceção dos quadros produzidos por estes imigrantes na Boa Vista, os restantes objetos são na sua quase totalidade importados do Senegal. A intensa produção de quadros torna-os omnipresentes na ilha. Para além de revestirem as paredes das lojas - que em muitos casos têm por nome "Galeria de Arte" -, são ainda usados na decoração de restaurantes, bares e pensões. Em Sal Rei, identifiquei 20 pintores (16 senegaleses e quatro originários da Guiné-Bissau, do Gana e da Nigéria); contudo, o seu número será certamente maior, uma vez que alguns quadros possuíam assinaturas de pessoas que se encontravam temporariamente no Senegal ou na ilha do Sal.

O grosso desta produção pode ser agrupado em duas categorias distintas. Em primeiro lugar, a pintura em acrílico sobre tela com colagens de pequenas tiras de tecidos wax print. Estes quadros são muito idênticos, variando a cor e os desenhos em torno das tirinhas de tecido que, quase sempre, dão forma a corpos femininos esguios e estilizados, com potes, feixes de lenha ou balaios sobre a cabeça. Em tamanhos que podem variar entre os 15 centímetros e um metro de largura, são vendidos entre 5 e 30 euros, não obstante os preços serem sempre negociáveis.

Em segundo lugar, encontramos um conjunto de quadros com colagem de areia colorida sobre tela ou madeira, com dimensões e preços idênticos aos da categoria acima exposta. Os motivos são bastante mais diversificados, embora também seja possível encontrar padrões temáticos que variam entre os ditos "motivos africanos" (choupanas, mulheres a pilar ou a carregar crianças ou objetos) e boa-vistenses (predominantemente tartarugas) e nos quais se inscrevem as marcas "No stress", "Cabo Verde" ou "Boa Vista". Em ambas as categorias, todos os pintores que contactei começaram a produzir estes quadros em Cabo Verde, queixando-se da forte concorrência que não permite elevar os preços.

\section{Das acusações de assédio à resposta "No stress"}

Todos os comerciantes que se encontram há mais anos na Boa Vista referem que este negócio seria muito mais rentável há 15 anos, apesar de existirem então menos turistas. De acordo com os seus testemunhos, não só os objetos 
seriam então vendidos pelo dobro do valor atual, como o volume de vendas seria superior.

Entre as razões apontadas pelos comerciantes para a atual carência de vendas encontra-se a concorrência que fez diminuir preços e clientes, o facto de os turistas saírem pouco dos hotéis, que possuem as suas próprias lojas de artesanato, ${ }^{24}$ a crise económica na Europa e sobretudo aquilo que consideram ser "a guerra" desencadeada pelos boa-vistenses contra os comerciantes de artesanato do continente africano e que tende a ser associada ao racismo. ${ }^{25}$ De facto, estes imigrantes foram sistematicamente acusados não apenas de venderem objetos não representativos da cultura cabo-verdiana, mas também de "assediarem" os turistas e desta forma ameaçarem a continuidade do crescimento do turismo na ilha.

A expressão "assédio aos turistas", que causa estranheza por não indicar a qualidade do assédio em causa, instalou-se no arquipélago, sendo reproduzida acriticamente por órgãos de comunicação social para designar duas técnicas de venda usadas por alguns comerciantes: a insistência e a abordagem na rua. A generalização do uso desta expressão não pode deixar de ser lida no âmbito de um padrão discursivo assente na discriminação destes imigrantes, nomeadamente na criminalização das suas atividades e na inversa vitimização dos turistas, entendidos como sujeitos que devem ser protegidos dos supostos perigos do "outro", africano. Atente-se no seguinte excerto de uma notícia relativa à ilha do Sal, intitulada: "Assédio aos turistas preocupa a população local":

"A mesma ['gerente de uma operadora turística' do Sal] adianta ainda que há quem afirme que ao sair do hotel já chegou a sofrer mais de 10 tentativas de assédio. O assunto está a 'passar dos limites', segundo os nossos entrevistados, pois para além do assédio, estes comerciantes passam-se por cabo-verdianos, alegando de forma 'enganosa', que os produtos artesanais que vendem são 'genuinamente cabo-verdianos' " (Anónimo s/d., presumivelmente de 2014, itálicos meus).

Veja-se ainda o artigo de $A$ Semana de 26/09/2009, também relativo à mesma ilha:

24 Os cinco maiores hotéis da Boa Vista detinham, no total, dez lojas com artesanato: o Marine Club e o Royal Decameron possuíam duas lojas, o Iberostar detinha quatro lojas e o Riu Karamboa e Riu Touareg juntos detinham também quatro lojas. Seis destas dez lojas pertenciam às cadeias Baobab (que comercializava objetos importados do Brasil) e Bazar \& Co. Apenas a loja My Boa Vista, no Marine Club, exibia um conjunto significativo de artefactos produzidos por artesãos cabo-verdianos de outras ilhas.

25 Sobre racismo e imigração em Cabo Verde, ver Rocha (2009) e Furtado (2012). 
"A polícia de fronteira está a identificar, para posterior expulsão, 11 cidadãos senegaleses que se encontravam a viver ilegalmente em Cabo Verde. Estes integravam um grupo constituído por 30 cidadãos da costa africana detidos pela Polícia Nacional na passada sexta-feira na Vila de Santa Maria a tentar impingir artesanato aos turistas" (Anónimo 2009, itálicos meus).

Apesar dos episódios de agressões físicas perpetradas pela Polícia de Ordem Pública de Santa Maria (Sal) sobre vendedores ambulantes senegaleses terem sido frequentes, muito raramente foram objeto de notícia na imprensa cabo-verdiana.

Como forma de combater as acusações de "assédio", várias lojas da Boa Vista exibem placas com a expressão "No stress", sugerindo que não pressionam os turistas a comprar. Remetendo simultaneamente para a propalada serenidade e indolência da ilha, a utilização do slogan "No stress" por parte destes comerciantes constitui uma máscara que muitas vezes encobre quotidianos ansiosos, decorrentes da imperativa necessidade de vender, da incerteza (Jung 2013) e da exclusão.

\section{CONSIDERAÇÕES FINAIS}

Ao longo do século XIX e grande parte do século XX, os discursos sobre cultura material espelharam os processos de imaginação de várias nações europeias. Embora com contornos distintos, esta mesma articulação manifesta na seleção dos elementos materiais da cultura revelou-se basilar na construção nacional de vários países africanos recém-independentes, durante as décadas de 1960 e 1970. Em Cabo Verde, esta articulação foi complexificada por um conjunto de tensões decorrentes da especificidade da construção da nação cabo-verdiana. Esta construção tem sido pensada como um processo de instrumentalização da crioulidade, enfatizando, em diferentes períodos, uma ou outra das duas categorias (África e Europa) que a constituem, refletindo assim variações no valor e dimensão atribuídos à componente africana.

Como foi visto, uma parte significativa do discurso erudito sobre artesanato emergiu no arquipélago no seio das críticas a Gilberto Freyre efetuadas pelos "claridosos" a propósito das definições da cultura cabo-verdiana, considerada mais africana pelo primeiro do que pelos segundos, que a entenderam como um caso de regionalismo português. Assinalo ainda o facto de a inscrição institucional do artesanato na construção nacional ter sido operada nos primeiros cinco anos após a independência, coincidentes com o período de unidade com a Guiné-Bissau, marcado pelo africanismo do PAIGC. A partir desta fase, muitos artefactos passaram a ser investidos de uma nova missão: representar a nação. Desta missão, decorre, quanto a mim, a quase obsessiva preocupação com o artesanato no presente, consubstanciada num combate pela determinação dos 
objetos que podem traduzir a cabo-verdianidade contemporânea, num tempo marcado pelo turismo.

$\mathrm{Na}$ Boa Vista - a ilha geograficamente mais próxima do continente, mas que tem sido descrita como uma das mais afastadas em termos culturais (Almeida 2003: 96) -, o crescimento do turismo e da imigração proveniente da CEDEAO constitui uma nova moldura para a afirmação da cabo-verdianidade. Contudo, as componentes desta nova moldura (turistas europeus e imigrantes africanos) assemelham-se de forma confrangedora às componentes que estiveram na origem do longo processo que a urdiu: escravos negros e senhores brancos.

Os discursos identitários dos boa-vistenses parecem agora encravar-se no abismo que separa o poder do ócio turístico europeu e a subalternidade do trabalho dos imigrantes africanos, equiparados a escravos em setores como o da construção civil e destituídos de muitos direitos pela sua situação de clandestinidade. Nesta nova moldura, amplificam-se nesta ilha autodefinições assentes em visões branqueadoras sobre a sua cultura, que celebram a componente europeia e submergem ou esconjuram a africana, bem explícitas em práticas e discursos discriminatórios em relação aos comerciantes senegaleses. Nas imagens da crioulidade que os boa-vistenses aspiram a transmitir aos turistas, estes comerciantes e os seus objetos constituem o material excluído e esconjurado, ${ }^{26}$ e o "fantasma do africano negro" referido por Miguel Vale de Almeida, que se quer continuar a aprisionar simbolicamente "no território continental, do qual as ilhas se encontram seguramente separadas por oceano" (2004: 10). ${ }^{27}$

Todavia, para os turistas, maioritariamente ingleses e alemães que elegem esta ilha como destino de férias pela beleza das suas praias, o facto de a Boa Vista pertencer a um país africano pode constituir um acréscimo de atratividade. Desconhecendo, na sua maioria, as vicissitudes do processo de imaginação nacional neste país, muitos destes turistas não diferenciam senegaleses e cabo-verdianos, nem os seus objetos, vistos como igualmente africanos.

Na verdade, para estes "consumidores transestéticos" (Lipovetsky e Serroy 2014 [2013]: 69), pouco preocupados com a autenticidade da sua experiência turística, os objetos vendidos pelos imigrantes parecem ser mais atrativos. Desde logo, pelo lastro da sua própria história enquanto símbolos da invenção e apropriação da alteridade de África pela Europa (Mudimbe 2013 [1994], 2013 [1988]; Mbembe 2014 [2013]). Apesar da sua despromoção a fakes ou "arte de aeroporto", muitos destes objetos carregam ainda uma carga de

26 Podendo, contudo, constituir-se como objeto de desejo. Muitos cabo-verdianos usam estes objetos na decoração das suas casas e algumas lojas de produtos chineses vendem imitações em plástico de estatuária dita africana. Em algumas áreas do artesanato cabo-verdiano, em especial na costura e bijuteria, assiste-se também a uma propagação do uso de tecidos estampados importados do Senegal.

27 Ver também Rocha (2013: 16). 
distinção herdada de estatutos atribuídos a objetos seus parentes, etiquetados, em diferentes períodos, como fetiches, curiosidades, objetos etnográficos e/ou arte africana (Steiner 1994; Clifford 2001 [1988]). São, de resto, assinaláveis as semelhanças entre o discurso erudito sobre arte africana da primeira metade do século XX e os discursos dos comerciantes senegaleses na Boa Vista sobre os seus objetos. Entre estas semelhanças destaco a mesma opacidade sobre a origem e autoria dos objetos e a sua caracterização monolítica que anula a diversidade (Kasfir 1992), decorrendo nos dois casos de um real desconhecimento sobre a proveniência de muitos artefactos. Os comerciantes senegaleses manipulam em seu favor esse desconhecimento, sublinhando o cunho pan-africanista das suas lojas, onde se misturam máscaras de vários países, às quais se poderiam juntar objetos cabo-verdianos. ${ }^{28}$

Entendendo os suvenires na aceção de Susan Stewart (1996 [1993]: 135-136), enquanto objetos que exprimem distância (espacial e temporal) onde se condensam operações nostálgicas, exotizantes e fetichistas, os objetos provenientes do Senegal poderão ainda ser dotados de maior densidade simbólica. Embora muitos dos artefactos produzidos por artesãos cabo-verdianos (concentrados sobretudo nas ilhas de São Vicente e Santiago) deem suporte a narrativas sobre a cabo-verdianidade, instituindo-se como símbolos da nação - de que são exemplos os desenhos do pelourinho da Cidade Velha ou de trapiches nos quadros feitos a partir de fibras de bananeira -, grande parte dos turistas da Boa Vista não consegue descodificá-los, por desconhecer o significado destes elementos (ausentes nesta ilha) na cultura cabo-verdiana.

Como refere Nelson Graburn (1979 [1976]: 15), os suvenires não devem apenas ser baratos e portáteis, devem também ser compreensíveis, ou melhor, imediatamente reconhecíveis. Constituindo uma língua de contacto entre turistas e hospedeiros, formada a partir da fusão de um número mínimo de elementos estéticos e simbólicos dos dois grupos (Ben-Amos 1977), os suvenires tendem a adaptar-se às representações que os turistas possuem sobre o lugar que visitam. Nesta perspetiva, a autenticidade de um suvenir decorrerá mais da sua repetição (González 2008: 43), que o torna progressivamente inteligível, do que da sua estrita correspondência com as representações dos hospedeiros sobre a sua cultura. Deste modo, dificilmente os objetos acima referidos, produzidos por artesãos cabo-verdianos, conseguem concorrer com os seus rivais, imediatamente reconhecíveis como símbolos do continente e que, pela sua história, constituem metassuvenires do encontro assimétrico entre a Europa e a África, reproduzido pelo turismo. Também nesta última aceção, os objetos vendidos pelos comerciantes senegaleses poderão estar mais 
aptos a tangibilizar a imaterialidade da experiência turística na Boa Vista, fundada sobre esta assimetria.

De acordo com Christopher Steiner (1994: 4-7, 87), os wolof exerceram um papel vital no comércio de arte africana, instituindo-se como um dos principais grupos de mediação no trânsito destes objetos entre África e a Europa. ${ }^{29}$ No presente, uma parte da diáspora senegalesa, envolvida no comércio informal em várias cidades europeias e americanas, continua a deslocar objetos (nem sempre artesanais) entre continentes e a trabalhar com representações ocidentais sobre a cultura material africana. Se este comércio informal e amiúde ambulante tem provocado conflitos reveladores do racismo e xenofobia existentes em muitas destas cidades (europeias, americanas e também africanas), em Cabo Verde, esta conflitualidade apresenta traços específicos que não podem deixar de ser articulados com a história da construção nacional cabo-verdiana e com o papel do artesanato nesta construção.

29 A arte africana viria também a exercer um papel marcante na construção nacional senegalesa durante a presidência de Léopold Sédar Senghor (1960-1980), como ficou patente na realização, em Dacar, do Festival Mundial de Artes Negras, em 1966 (Ficquet e Gallimardet 2009). 


\section{BIBLIOGRAFIA}

ADEPOJU, Aderanti, s/d., "Operationalising the ECOWAS protocol on free movement of persons: prospects for sub-regional trade and development", disponível em < https:/www. gfmd.org/files/documents/AdepojuS8.pdf > (última consulta em janeiro de 2017).

ADIYIA, Bright, et al., 2015, "Analysing governance in tourism value chains to reshape the tourist bubble in developing countries: the case of cultural tourism in Uganda", Journal of Ecotourism, 14 (2-3): 113-129.

ALMADA, José Luís Hopffer, 2008, "Um excorço complementar à história e à cultura cabo-verdianas a partir do ano-miradouro de 2006”, em J. L. Hopffer Almada (org.), O Ano Mágico de 2006: Olhares Retrospectivos sobre a História e a Cultura Caboverdianas. Praia, IBNL, $31-130$.

ALMEIDA, Germano, 2003, Cabo Verde: Viagem pela História das Ilhas. Lisboa, Editorial Caminho.

ALMEIDA, Miguel Vale de, 2004, "Crioulização e fantasmagoria”, disponível em < http:// www.dan.unb.br/images/doc/Serie365empdf.pdf > (última consulta em janeiro de 2017).

ANJOS, José, 2002, Intelectuais, Literatura e Poder em Cabo Verde: Lutas de Definição da Identidade Nacional. Porto Alegre e Praia, IFCH/INIPC.

ANÓNIMO, 2009, "Cabo Verde prepara processo de expulsão de 11 cidadãos senegaleses", online em A Semana, < http://www.asemana.publ.cv/spip.php?article45688> (última consulta em janeiro de 2017).

ANÓNIMO, s/d., "Assédio aos turistas preocupa a população local", online em Ocean Press, $<$ http://www.oceanpress.info/cms/Pt/reportagem/7 125 -sal-assedio-aos-turistas-preocupa-a-populacao-local > (última consulta em janeiro de 2017).

BARbOSA, Carlos, 2014, Trânsitos no Atlântico: Experiências Migratórias no Arquipélago de Cabo Verde. Coimbra, Universidade de Coimbra, tese de doutoramento em Pós-Colonialismos e Cidadania Global.

BAVA, Sophie, 2005, "Variations autour de trois sites mourides dans la migration", Autrepart, 4 (36): 105-122.

BEN-AMOS, Paula, 1977, "Pidgin languages and tourist arts", Studies in The Anthropology of Visual Communication, 42 (2): 129-139.

CARreirA, António, 1983 [1968], Panaria Cabo-Verdeano-Guineense: Aspectos Históricos e Sócio-Económicos. Praia, Instituto Caboverdeano do Livro.

CLIFFORD, James, 2001 [1988], Dilemas de la Cultura: Antropología, Literatura y Arte en la Perspectiva Posmoderna. Barcelona, Editorial Gedisa.

COHEN, Erik, e Nir AVIELI, 2004, "Food in tourism: attraction and impediment", Annals of Tourism Research, 31 (4): 755-778.

DIOP, Momar-Coumba (org.), 2008, Le Sénégal des migrations: mobilités, identités et sociétés. Paris, Crepos-Karthala.

FALL, Papa Demba, e Jordi Garreta BOCHACA (orgs.), 2012, Les migrations africaines vers l'Europe: entre mutations et adaptation des acteurs sénégalais. Dakar, REMIGRAF-IFAN/GR-ASE Lleida, disponível em < http://www.geosoc.udl.cat/professorat/garreta/fall_et_bochaca_ 301013_ok.pdf > (última consulta em janeiro de 2017).

FERNANDES, Gabriel, 2002, A Diluição da África: Uma Interpretação da Saga Identitária Cabo-Verdiana no Panorama Político (Pós)Colonial. Florianópolis, Editora da UFSC. 
FERNANDES, Gabriel, 2006, Em Busca da Nação: Notas para Uma Reinterpretação do Cabo Verde Crioulo. Florianópolis e Praia, Editora da UFSC/IBNL.

FERREIRA, Manuel, 1967, A Aventura Crioula. Lisboa, Ulisseia.

FICQUET, Eloi, e Lorraine GALLIMARDET, 2009, "On ne peut nier longtemps l'art nègre", Gradhiva, 10: 134-155, disponível em < http://gradhiva.revues.org/1560 > (última consulta em janeiro de 2017).

FIKES, Kesha, 2007, "Emigration and the spatial production of difference from Cape Verde", em Nancy Naro, R. Sansi-Roca e D. Treece (orgs.), Cultures of the Lusophone Black Atlantic. Nova Iorque, Palgrave Macmillan, 159-173.

FREIRE-MEDEIROS, Bianca, e Celso CASTRO, 2007, "A cidade e seus souvenires: o Rio de Janeiro para o turista ter", Revista Brasileira de Pesquisa em Turismo, 1 (1): 34-53, disponível em < https://rbtur.org.br/rbtur/article/view/78 > (última consulta em janeiro de 2017).

FREYRE, Gilberto, 2001 [1953], Aventura e Rotina. Rio de Janeiro, Topbooks.

FURTADO, Clementina, 2012, As Migrações da África Ocidental em Cabo Verde: Atitudes e Representações. Praia, Uni-CV/UlB, tese de doutoramento em Ciências Políticas e Sociais.

GONZÁLEZ, Fernando, 2008, “Narrativas de seducción, apropiación y muerte o el souvenir en la época de la reproductibilidad turística", Acto: Revista de Pensamiento Artístico Contemporáneo, 4: 34-49, disponível em < http://reacto.webs.ull.es/pdfs/n4/estevez.pdf > (última consulta em janeiro de 2017).

GRABURN, Nelson, 1979 [1976], "Introduction: the arts of the fourth world", em Nelson Graburn (org.), Ethnic and Tourist Arts: Cultural Expressions from the Fourth World. Berkeley e Los Angeles, University of California Press, 1-32.

HORODYSKI, Graziela, F. MANOSSO, e José GÂNDARA, 2012, "A pesquisa narrativa na investigação das experiências turísticas relacionadas ao consumo de souvenirs: uma abordagem fenomenológica”, disponível em < http://www.academia.edu/2761684/A_pesquisa_narrativa_na_investigacao_das_experiencias_turisticas_relacionadas_ao_consumo _de_souvenirs_uma_abordagem_fenomenologica > (última consulta em janeiro de 2017).

INE, 2005, Estatísticas do Turismo, 1999-2004. Praia, INE.

INE, 2012, Estatísticas do Turismo, 2011. Praia, INE.

INE, 2013, Estatísticas do Turismo: Movimentação de Hóspedes, 2012. Praia, INE.

INE, 2014, Estatísticas do Turismo: Movimentação de Hóspedes, 2013. Praia, INE.

INE, 2015, Anuário Estatístico, 2015. Praia. INE.

INE, 2016, Estatísticas do Turismo, 2015. Praia, INE.

INE, s/d., "Evolução da população residente em Cabo Verde por ilha concelho (1900-2010)", disponível em < http://www.renow.itccanarias.org/images/policy/cabo_verde/marco_gen eral/evolucao_da_populacao_residente_em_cabo_verde_1900_-2010.pdf > (acesso em 24/04/2016).

JAAKSON, Reiner, 2004, "Beyond the tourist bubble? Cruiseship passengers in port", Annals of Tourism Research, 31 (1): 44-60.

JUNG, Philipp, 2013, The Dynamics of Migration and their Impact on the Country of Origin: A Case Study of Senegalese Labour Migrants on the Cape Verdean Island Boa Vista and Their Relatives at Home. Lisboa, ISCTE-IUL, tese de mestrado em Estudos Africanos.

KASFIR, Sidney, 1992, "African art and authenticity: a text with a shadow", African Arts, 25 (2): 40-97. 
LADD, Katherine, 2012, A Handmade Future: The Impact of Design on the Production and Consumption of Contemporary West African Craft as a Tool for Sustainable Development, Brighton, University of Brighton, tese de doutoramento, disponível em $<$ http://eprints.brighton. ac.uk/12343/ > (última consulta em janeiro de 2017).

LANÇA, Marta, 2010, "Da resistência e da fantasia, entrevista a Luísa Queirós”, disponível online em Buala, < http://www.buala.org/pt/cara-a-cara/da-resistencia-e-da-fantasia-entrevista-a-luisa-queiros > (última consulta em janeiro de 2017).

LEAL, João, 2009, “Da arte popular às culturas populares híbridas”, Etnográfica, 13 (2): 472 -476, disponível em < https://etnografica.revues.org/1318> (última consulta em janeiro de 2017).

LIMA, A. Germano, 1997, Boavista: Ilha de Capitães (História e Sociedade). Praia, Spleen Edições.

LIMA, Ricardo Gomes, 2009, "Arte popular e artesanato: falamos da mesma coisa?”, Ciências Humanas e Sociais em Revista, 31 (1): 97-101.

LIPOVETSY, Gilles, e Jean SERROY, 2014 [2013], O Capitalismo Estético na Era da Globalização. Lisboa, Edições 70.

LOPES, Baltasar, 2010 [1956], "Cabo Verde visto por Gilberto Freyre”, Escritos Filológicos e Outros Ensaios. Praia, IBN, 229-275.

LOPES, Leão, 1983, “Olaria caboverdiana. Que futuro?”, Ponto \& Virgula, 2: 13-15.

LOPES FILHO, João, 1984, “Conversando com Mesquitela Lima”, Ponto \& Vírgula, 10-11: 17-22.

MADUreIRA, Tânia, 2012, A Revitalização da Olaria em Trás di Munti e os Seus Significados Locais: Loiça Pintada Não É Património? Coimbra, Universidade de Coimbra, tese de mestrado em Antropologia Social e Cultural.

MARÇAL, Artur, 2012, A Tradição da Olaria em Fonte Lima. Viana do Castelo, Instituto Politécnico de Viana do Castelo, tese de mestrado em Educação Artística.

MARCElino, Pedro, 2011 , The New Migration Paradigm of Transitional African Spaces: Inclusion, Exclusion, Liminality and Economic Competition in Transit Countries. A Case Study on the Cape Verde Islands. Saarbrücken, Lambert.

MBEMBE, Achille, 2014 [2013], Crítica da Razão Negra. Lisboa, Antígona.

MIRANDA, Nuno de, 1968, "Cabo Verde", em Fernando Pires de Lima (org.), A Arte Popular em Portugal: Ilhas Adjacentes e Ultramar, vol. I. Lisboa, Editorial Verbo, 319-376.

MUdimbe, V. Y., 2013 [1988], A Invenção de África: Gnose, Filosofia e a Ordem do Conhecimento. Ramada e Luanda, Edições Pedago e Edições Mulemba.

MUDimbe, V.Y., 2013 [1994], A Ideia de África. Ramada e Luanda, Edições Pedago e Edições Mulemba.

POEZE, Miranda, 2010, In Search of Greener Pastures? Boat-Migrants from Senegal to the Canary Islands. Leiden, African Studies Centre.

ROCHA, Eufémia, 2009, "Mandjakus São Todos os Africanos, Todas as Gentes Pretas que Vêm de África”: Xenofobia e Racismo em Cabo Verde. Praia, Universidade de Cabo Verde, tese de mestrado em Ciências Sociais.

ROCHA, Eufémia, 2013, “Migração na África Ocidental e Cabo Verde: uma relação recente?”, Ciências Sociais Unisinos, 49 (1): 12-19.

SALL, Leyla, 2010, "Les champs commerciaux sénégalais à Paris: coprésences, luttes pour l'espace et stratégies commerciales au sein d'espaces urbains interstitiels", Diversité Urbaine, 10 (1): 61-83. 
STEINER, Christopher B., 1994, African Art in Transit. Cambridge, Cambridge University Press.

STEWART, Susan, 1996 [1993], On Longing: Narratives of the Miniature, the Gigantic, the Souvenir, the Collection. Durham e Londres, Duke University Press.

SWANSON, Kristen, e Patricia E. HORRIDGE, 2006, "Travel motivations as souvenir purchase indicators”, Tourism Management, 27: 671-683.

SWANSON, Kristin, e Dallen J. TIMOTHY, 2012, "Souvenirs: icons of meaning, commercialization and commoditization”, Tourism Management, 33: 489-499.

UCI, 2012, Estratégia Nacional de Imigração: Resolução n. ${ }^{\circ}$ 3/2012, de 23 de janeiro. Praia, Unidade de Coordenação da Imigração, disponível em < http://www.dgi.com.cv/?wpd$\mathrm{mdl}=3714>$ (última consulta em janeiro de 2017).

UCI/OFII, 2014, Estudo de Diagnóstico: Identificação das Necessidades dos Imigrantes no Processo de Integração Social em Cabo Verde. S/l., Unidade de Coordenação de Imigração (UCI) e Office Français de l'immigration et de l'intégration (OFII), disponível em < http://www. dgi.com.cv/?wpdmdl=3769 > (última consulta em janeiro de 2017).

URRY, John, e Jonas LARSEN, 201 1, The Tourist Gaze 3.0. Londres, Sage.

VENÂNCIO, José, e João SILVA, 2010, "Especificidades da arte cabo-verdiana: Manuel Figueira, de artista nacional em Cabo Verde a artista outsider em Portugal", Aurora, 8, disponível em < http://www.pucsp.br/revistaaurora/ed8_v_maio_2010/artigos/ed/8_artigo. htm > (última consulta em janeiro de 2017).

VENKATESAN, Soumhya, 2009, "Rethinking agency: persons and things in the heterotopia of 'traditional Indian craft'", Journal of the Royal Anthropological Institute, 15: 78-95. 